\title{
Teachers' Perspectives on Teacher Training for Better Implementation of GIS in the Geography Classroom
}

\section{Selected Results from Group Discussions with Geography Teachers in Germany}

\author{
Steffen Höhnle ${ }^{1}$, Rainer Mehren ${ }^{2}$ and Jan Christoph Schubert ${ }^{3}$ \\ ${ }^{1}$ Friedrich-Alexander-Universität, Erlangen-Nürnberg, Germany·steffen.hoehnle@fau.de \\ ${ }^{2}$ Justus-Liebig-Universität Gießen, Germany · rainer.mehren@geogr.uni-giessen.de \\ ${ }^{3}$ Westfälische Wilhelms-Universität, Münster, Germany · jcschubert@uni-muenster.de
}

Full paper double blind review

\begin{abstract}
The perspective of German geography teachers was examined regarding their view on what university teacher training has to provide in order to improve the implementation of GIS in the classroom. This was based on the finding that there is only low implementation of GIS in geography classrooms at German schools, despite teachers seeing enormous potential in GIS usage in general.

The results show that one of the eight main criteria that is important for the implementation of GIS from teachers' perspectives on the integration of GIS in teacher training is especially challenging in the university context; however, concrete measures for the design of university and practical courses in teacher training can be derived easily.
\end{abstract}

\section{Presentation of the Problem}

The potential of GIS ${ }^{1}$ for geographic education and for geography as a discipline in general has been widely published (see BAKER 2002, FAVIER \& VAN DER SCHEE 2009, VOGLER et al. 2010, and others). There is broad consensus both in the scientific discourse, as well as in research results about teachers' perspectives (see SCHUBERT et al. 2012) that GIS offers great opportunities for learning, especially in the school context. Another notable research finding that should be highlighted here is that the implementation of GIS in geography classrooms in Germany is still really low (see HöHNLE et al. 2010), a state, which is also true for many other countries. In this paper we will address teachers' perspectives on what teacher training has to provide to change this situation.

\footnotetext{
1 In this paper the term GIS includes tools like Google Earth, which is usually not considered to be a true Geographic Information System.
} 


\section{Research Design and Methodology}

In the course of an earlier research project we found that the implementation of GIS in German geography classrooms is quite low, despite teachers seeing great potential in GIS (see HÖHNLE et al. 2011, SCHUBERT et al. 2012). However, they also see great impediments for GIS work in the classroom. Teachers were confronted with these findings during focus group discussions, which aimed at dealing with the current status and problems constructively, and developing criteria for better implementation of GIS in close consideration of the perception of the actors who actually play the leading role in the implementation process (ZEITLER et al. 2012, 23 ff.). Thus, six focus group discussions (BOHNSACK 2004) took place, five of which included homogenous groups and one a quite heterogeneous group: (1) students of geographic education, (2) students in teacher training in geography (German expression: Studienreferendare), (3) GIS inexperienced teachers, (4) GIS experienced teachers, (5) GIS trainers, and (6) a heterogeneous group of inexperienced teachers, experienced teachers and students). Each group included four to six participants. The trigger for discussion was the confrontation of the participants with the results of the above-mentioned earlier study about barriers for the implementation of GIS. During the discussions the groups came up with ideas and positive examples from their perspectives on how to face existing barriers and how to boost implementation. Content analysis methodology (MAYRING 2000) was used to analyze the focus group discussions. In doing so, several criteria could be derived to take into account when targeting better implementation of GIS in the geography classroom.

The transcription of the audio recordings of the group discussions (KOWAL \& O'CONNELL 2004) was followed by an editing process, in order to get a more accessible revised version of the transcript. We then determined categories as well as respective levels of abstraction in close consideration of the research question. This was followed by the formulation of inductive categories out of the material with the goal of subsuming the old categories or formulating new, more suitable categories. The additional process included a revision of the categories, further text work, and the interpretation of the results. This process was accompanied by a summative and a formative check of reliability.

We coded the material and developed the categories using the software MAXQDA (BOS \& TARNAI 1999) in an independent process by two researchers. Afterwards the results were compared and intercoder reliability was determined in order to secure the quality of the analysis process. In doing so, a procedure was used, which illustrates the congruousness of the developed codings on a percentage basis (see HOLSTI 1969, p. 140). The computation of intercoder reliability (congruous codings of different coders) delivered high values of $\mathrm{R} \geq .72$ for the particular codes; the mean value for congruous codings was .78. For the criterion, teacher training' intercoder reliability was .837 ; therefore, we can say that coding objectivity was quite high. In regard to time-displaced reanalysis performed by the first coder of the material (= intracoder reliability) the value was even higher (.898).

Finally we summarized all the material coded within one category in a summarizing content analysis (MAYRING 2004). The result is an overview of generalized criteria for successful implementation of GIS from the perspective of geography teachers. We then supplemented these criteria with further theoretical and empirical findings from scientific literature in the field. 
A rule-governed, stepwise and methodically controlled process not only aimed at quality assurance, but also at intersubjective inferability through independent analysis, reciprocal control by different analyzing researchers, and discussions of the steps of interpretation within a workgroup. The quality of the methodical proceeding can be judged based on a well-reasoned, transparent and exactly documented procedure.

\section{Results: Teacher Training}

Eight main criteria for successful implementation of GIS could be derived in general from the group discussions with geography teachers: integration of GIS in initial teachers' training, adequate teaching examples, sustainable in-service teachers' training activities, didactical conditions, GIS-promoting conditions at the school, cooperation and exchange of the participating GIS actors, access and availability of geodata, and adequate software solutions (see Figure 1).

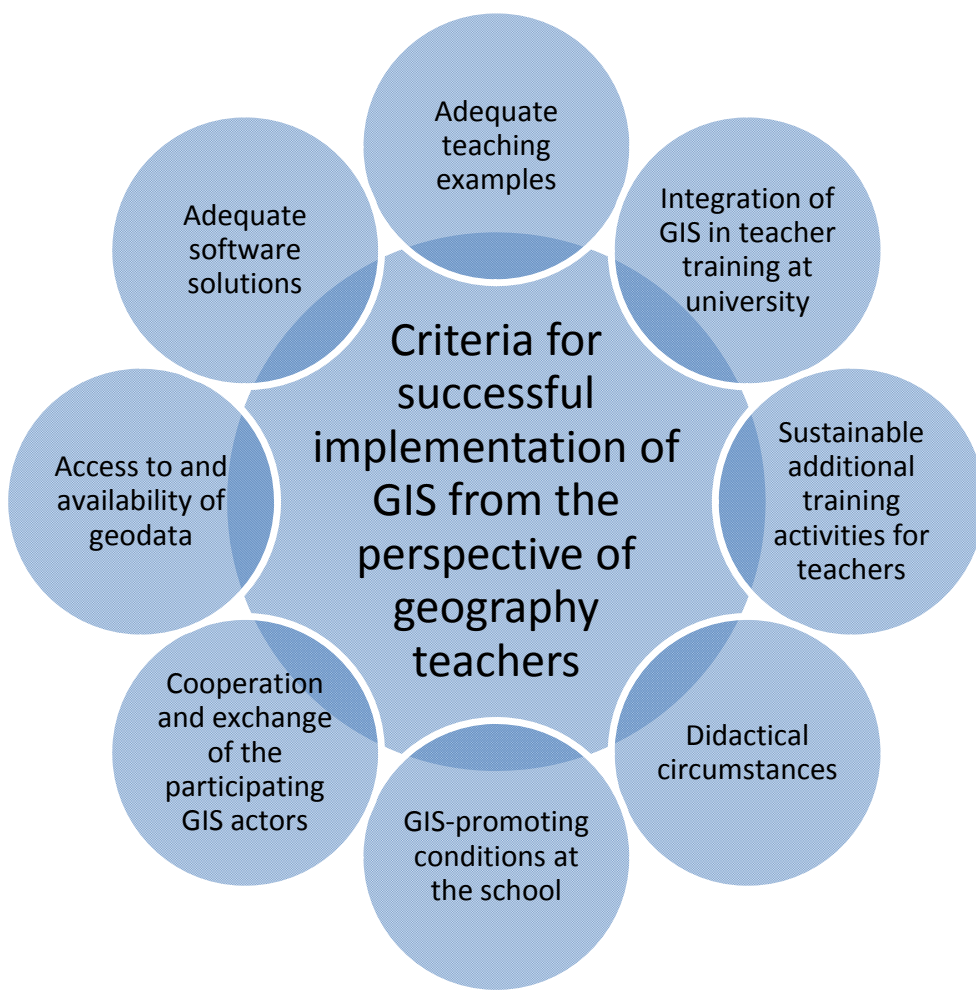

Fig. 1: Criteria for successful implementation of GIS from the perspective of geography teachers in Germany

These rather general criteria can be differentiated into sub-criteria, in which we will address the main criterion "integration of GIS in teacher training at university" in this paper (see 
Figures 2 and 3), and the closely related results for the second phase of teacher training ("Referendariat").

There are six sub-criteria that are essential from teachers' perspectives regarding teacher training at university. These sub-criteria will be described shortly and illustrated by a quote from the group discussions, which can be regarded as an example of various other quotes of similar nature.

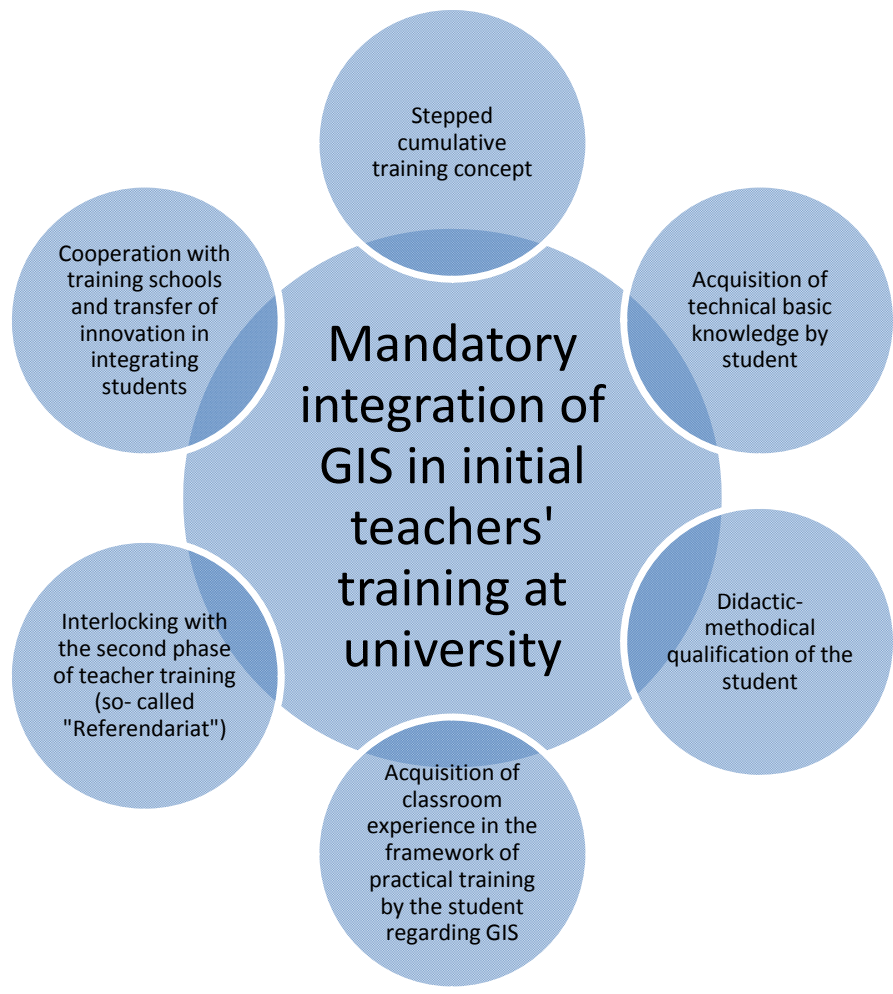

Fig. 2: Overview of the sub-criteria regarding the main criterion "integration of GIS in initial teachers' training"

Almost all of the teachers that participated in the focus group discussion recognized the general importance of GIS integration into teacher training. The following quotes illustrate this point, but also illustrate discontent with the experienced training:

"Well, I would say by all means, this has to be part of teacher training. In the second phase at the latest."

"Teacher trainees! At university already, not only in the second phase. This has to happen earlier!"”

"And I find that it [integration of GIS] is by all means a step which has to be part of teacher training of course and of course continuous teacher training is very important here as well. Yes, this is absolutely necessary." 


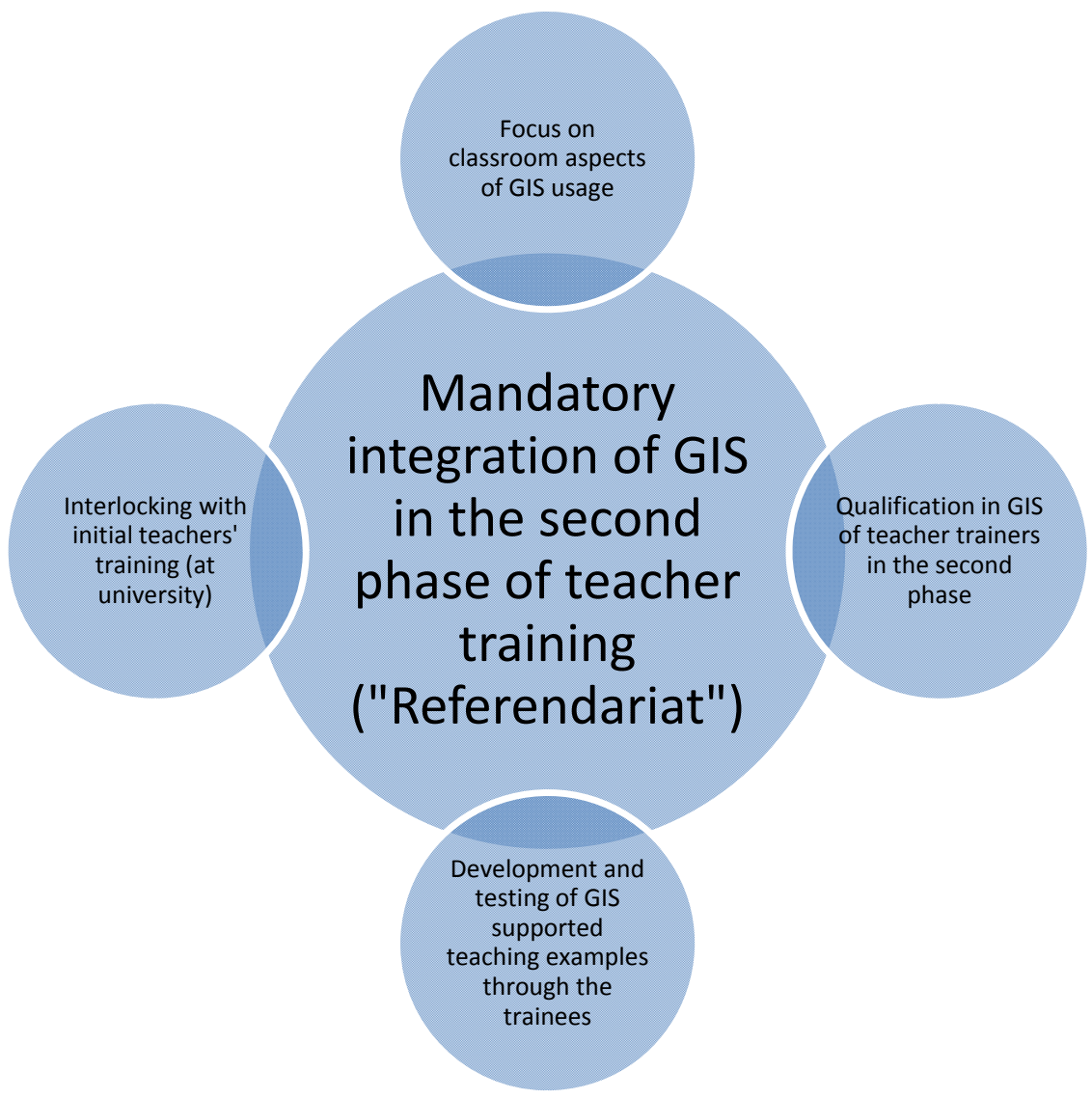

Fig. 3: Overview of the sub-criteria regarding the second phase of teacher training

\subsection{Acquisition of Technical Basic Knowledge by Student}

From the point of view of the teachers, it is essential that basic technical knowledge is already acquired during the initial teacher training at university. In the school context they believe that this often time-consuming process cannot be mastered, especially against the background of many other challenges young teachers face. Another aspect is that getting acquainted with applications early on is considered to be a suitable countermeasure against fear of the complexity of the program, which most of the teachers in the group discussions have noticed.

"Well, that is why teacher trainees of the second phase have to arrive at school and need to have a clue already. Because if they are at the school, if they are 'frozen' as a trainee in the second phase then, then they certainly won't deal with GIS, because they have to do so many other things..."

"They simply would have to be mentored in it during their university studies so that they really have good basic practical knowledge to handle the software application." 
"We got two young colleagues in the last two years, one of them is an incredibly thankful 'customer' in GIS training in continuous teacher education. He is somebody who has already done that at university. And people like that only need an 'aha' experience once again, yes that's the way it worked. That guy will be the first one to work with GIS really quickly. I'm sure about that, he will manage that this year."

\subsection{Didactic-methodical Qualification of the Student}

Teachers also feel that more didactic-methodical work has to be done at university during the initial teachers' training. This starts with better support in didactic-methodical questions of trainees so that they can work more effectively with the tools in the classroom. But it is also important that teachers see added value in the usage of GIS (e.g., concerning the effectiveness of GIS for pupils' learning processes), added value that is empirically proven so that other teachers and designers of curricula for example can be convinced of the potential of GIS. This, along with the presentation of added value in close consideration of geographic questions or topics, supported by detailed and suitable teaching material, is a good way to go from the perspective of teachers. Questions like which application is suitable for which grade, or how to combine GIS with questions of daily life, how to activate pupils cognitively but also address difficulties in GIS work with pupils, and how to handle these difficulties are important here as well. This illustrates that technical knowledge is important and necessary of course, but without didactical and concrete classroom knowledge, work with GIS lacks a connection to the school context, which consequently is not sufficient and suitable.

"I expect didactics to clarify what they are doing now, which effect it has? In the end? Colleagues always expect that. Why should I use GIS? What is improved when you use it? Which competences can I promote? I really expect empirical research on that. Here university has plenty of possibilities."

"We should think about how to implement [GIS] didactically and methodically. I think that at university the didactical and methodical aspects are simply neglected."

"Didactics and methods [regarding GIS] have to be expanded and extended at university by all means."

\subsection{Acquisition of Classroom Experience in the Framework of Practical Training by the Student Regarding GIS}

Another aspect that teachers find really important is the acquisition of classroom experience using GIS early on. In this context practical courses in the framework of initial university teacher training play an important role from the point of view of teachers. Another aspect is cooperation between in-service teachers and students who are still in the initial teacher training stage at university. This cooperation is seen as beneficial for both groups.

"And if they at the university and we in the practical courses, if we get them in this direction a little bit already and if they find something like that later on in the school books for example, then I think this would help."

"Well, I can imagine, well we have the so-called 'Schulpraktikum' [practical course with teaching at a school during university training]. I think everywhere in Bavaria. Well then in the framework of such a practical course, the students then, they should teach some lessons here as well, not only watching teachers teach. They should come up with suggestions and ideas. And talk with the respective mentor, the teacher mentor. And arrange something." 
"Well, I think that this is a good way. That they use the knowledge they already have in the framework of the practical courses. I think no mentoring teacher would say: No, you are not allowed to. Well, if the preconditions are there in the computer rooms. Cooperation with training schools and transfer of innovation integrating students."

\subsection{Stepped Cumulative Training Concept}

Cumulative work with GIS is considered an integral part of teacher training from the point of view of the teachers. This means that in the initial teacher training basic technical knowledge should be addressed first; afterwards the focus should be didactic and concrete classroom potential, as well as possible difficulties when working with pupils. As a next step, teaching units already available can be analyzed critically, and perhaps be improved afterwards or individual teaching conceptions can be designed. These conceptions can be tested and reflected on in practical classes ("Schulpraktika"). In this context, coordination in teacher training between the different phases is really important. If dealing with GIS is already natural for the trainee at university then teaching with GIS becomes natural for them much easier as well. Against this background the various and very complex demands especially rather inexperienced teachers have to face are also an important aspect. Cumulative and coordinated approaches are the way to go here from the perspective of the teachers participating in the study.

"Well finally it is basically the same as with pupils. They start using an atlas in grade 5 and we build on that. It is the same here again: If we started with it at university, with building a foundation and then during the second phase of teacher training we continue so that okay, how do I do that as a teacher now, how do I make that accessible to pupils, then we would have this foundation already. And you don't just sit there in the beginning: Oh, now I would actually have to do that. I have to do so many things, how shall I handle this?"

\subsection{Second Phase of Teacher Training ("Referendariat"): Focus on Classroom Aspects of GIS Usage}

According to the teachers participating in the focus group discussions, the second phase of teacher training ("Referendariat") incorporates many difficulties, but also offers many chances for improving implementation of GIS in the geography classroom. First of all, the teachers consider the second phase of teacher training really dependent on the first phase of initial teacher training at university. Without basic knowledge of GIS stemming from university training in the second phase, GIS becomes really difficult or almost impossible in their opinion. Moreover, the focus in the second phase of teacher training should not be too much on theoretical understanding of GIS from a didactical perspective but rather on concrete teaching examples and individual teaching experiences and observations regarding GIS. The goal has to be the enrichment of knowledge of GIS with practical elements and to show potential and difficulties in the context of everyday teaching.

"Then in any case one would have completely different opportunities in the second phase basically, then, showing the didactical implications. Where can I use it? Which topics or questions are appropriate?"

"If we started with it at university, with building a foundation and then during the second phase of teacher training we continue so that okay, how do I do that as a teacher now, how do I make that accessible to pupils, then we would have this foundation already." 


\subsection{Qualification in GIS of Teacher Trainers in the Second Phase}

The teachers participating in the study observe teacher trainers of the second phase very critically. While there is great appreciation of the work being done in teacher training in general, the discussants describe the large variety of attitudes toward personal development, teaching, and the subject of geography itself. Some teacher trainers are described as being really progressive and open for new developments in the subject, others are described as rather traditional, too conservative or even reluctant to change outdated teaching practices. This circumstance should not be ignored when dealing with GIS implementation.

"All of the teacher trainers in the second phase. Yeah. There are some who are relatively open for it. We had such a teacher trainer in one of our courses in continuing teacher education. Because he has a teacher trainee who writes his thesis on it, he wants to learn that as well then. But there are also some teacher trainers in the second phase who I know: I won't allow such rubbish to get into geography. I really see difficulties with allencompassing implementation."

\subsection{Development and Testing of GIS-supported Teaching Examples by the Trainees}

The teachers participating in the study also see great potential in the teacher training of the second phase. Not only can trainees support one another when designing their first teaching units and teaching with GIS for the first few times, the exchange of teaching material and teaching units among the trainees in a training group is also seen as the best approach in the second phase. However, this exchange has to be organized, structured, and supervised by the teacher trainer.

"Well, I think that in a training group in the second phase of teacher training there actually is so much potential there. One could let each trainee design a GIS based teaching unit for one class and exchange that and in the end one has a GIS-based teaching unit for every grade."

\subsection{Interlocking with the First Phase of Teacher Training (at University)}

As mentioned already, the second phase of teacher training cannot be successful regarding work with GIS without preparation in the first phase. Not only models building on the foundation of the initial training phase at university are imaginable here, but also models really interlocking the two phases of teacher training. In doing so, teachers not only see benefits for each of the two phases, but also see potential for increasing the quality of teacher training as a whole.

\section{Conclusion}

Implementing GIS into the geography classroom is a challenging task and cannot be promoted without teacher trainers. University as well as practical training is challenged in this context. As the results of the teachers' perspectives on GIS implementation show, there are several concrete demands that teachers have for teacher training. These demands are indeed challenging and need resources, yet they deliver concrete criteria for teacher training and can give valuable support when designing initial training at university as well as practical 
training in classroom situations. The challenges and difficulties seen by the teachers should be regarded as constructive feedback and can be faced adequately. In addition, difficulties seen from the teachers' perspective can be surmounted.

Cooperation between teacher trainers of the different phases of teacher training is the way to go according to the teachers. In doing so, many of the different criteria the teachers see for teacher training that promotes GI implementation can be addressed. The importance of this result can be emphasized even more if we look back at the results from our partial study about barriers for implementation: here teachers who got training in GIS during their university training only saw lower barriers regarding technical aspects of GIS usage but not regarding didactic-methodical aspects (see HöHNLE et al. 2011). An obvious explanation for this is that GIS at university is rather about training in the usage of GIS tools, but neglects didactic-methodical preparation for the job of teaching. We also find this argument in most of the group discussions: technical basic knowledge and didactic-methodical qualifications for teaching are necessary if we want to improve implementation. The integration of GIS into teacher training in this way can be regarded as the central most important step. However, it should not be withheld that this requires resources as well as involvement and dedication of the trainers involved. Organizational support of universities, as well as from the school and educational administration is necessary in this context as well.

\section{References}

BAKER, T. R. (2002), The effects of Geographic Information System (GIS) technologies on students' attitudes, self-efficacy, and achievement in middle school science classrooms. $\mathrm{PhD}$ Dissertation. The University of Kansas, School of Education.

BoHnsack, R. (2004), Group discussion and focus groups. In: Flick, U., KARDOFF, E. \& VON STEINKE, I. (Eds.), A companion to qualitative research, 214-221.

Bos, W. \& TARNAI, B. (1999), Content analysis in empirical social research. International Journal of Educational Research, 31, 659-671.

FAVIER, T. \& VAN DER SCHEE, J. (2009), Learning to think geographically by working with GIS. In: JeKel, T., Koller, A., Donert, K. \& Vogler, R. (Eds.), Learning with geoinformation IV. Wichmann, Heidelberg, 135-145.

HöHnle, S., Schubert, J. C. \& Uphues, R. (2010), The frequency of GI(S) use in the geography classroom. Results of an empirical study in German secondary schools. In: JeKel, T., Koller, A., DONERT, K. \& Vogler, R. (Eds.), Learning with geoinformation V. Wichmann, Berlin/Offenbach, 148-158.

HöHnle, S., Schubert, J. C. \& Uphues, R. (2011), Barriers to GI(S) use in schools. A comparison of international empirical results. In: JEKEL, T., KOLLER, A., DONERT, K. \& VOGLER, R. (Eds.), Learning with geoinformation V. Wichmann, Berlin/Offenbach, 124-134.

Holsti, O. R. (1969), Content analysis for the social sciences and humanities. AddisonWesley, $256 \mathrm{p}$.

Kowal, S. \& O'CONNELl, D. C. (2004), The transcription of conversations. In: FLICK, U., KARDOFF, E. \& VON SteInke, I. (Eds.), A companion to qualitative research. SAGE, 248-252.

MAYRING, P. (2000), Qualitative content analysis. In: Qualitative social research. http://www.qualitative-research.net/index.php/fqs/article/view/1089/2385 (18 Jan. 2015). 
MAYRING, P. (2004), Qualitative content analysis. In: FliCK, U., KARDOFF, E. \& VON STEINKE, I. (Eds.), A companion to qualitative research. SAGE, 266-269.

SCHUBERT, J. C., HöHnLE, S. \& UphueS, R. (2012), Which chances do teachers see in GI(S) usage in the classroom? Selected results from a survey of geography teachers in Germany. In: Jekel, T., CAr, A., Strobl, J. \& Griesebner, G. (Eds.), GI forum 2012: geovizualisation, society and learning. Wichmann, Berlin/Offenbach, 283-291.

Vogler, R., AHAMER, G. \& JeKEL, T. (2010), GEOKOM-PEP - Pupil led research into the effects of geovisualization. In: JeKel, T., Koller, A., DONERT, K. \& Vogler, R. (Eds.), Learning with geoinformation V. Wichmann, Berlin/Offenbach, 51-60.

Zeitler, S., Heller, N. \& Asbrand, B. (2012), Bildungsstandards in der Schule. Eine rekonstruktive Studie zur Implementierung der Bildungsstandards. Waxmann. 